\title{
Comunicação
}

[Communication]

\section{Condenação de fígados bovinos na região sul do estado do Espírito Santo}

\author{
[Condemnation of bovine liver in the southern region of the State Espirito Santo, Brazil] \\ N.P. Vieira ${ }^{1}$, P.B. Faria ${ }^{2 *}$, M.R. Mattos ${ }^{2}$, A.A. Pereira ${ }^{3}$ \\ ${ }^{1}$ Instituto de Defesa Agropecuária e Florestal do Espírito Santo - IDAF, ES \\ ${ }^{2}$ Universidade Federal de Lavras - UFLA \\ Caixa Postal 3037 \\ 37200-000 - Lavras, MG \\ ${ }^{3}$ IFMG - Campus Bambuí - Bambuí, MG
}

Os produtos de origem animal, em especial os cárneos, por desempenharem papel importante na alimentação humana em razão de seu valor nutricional (Lawrie, 2005), não podem servir como via de transmissão de doenças. A condenação de órgãos, vísceras e carcaças de animais destinados ao abate pelo Serviço de Inspeção Veterinário é importante para a saúde pública, pois muitas das alterações patológicas são decorrentes de zoonoses (Herenda et al., 1994).

Os dados utilizados para realização deste estudo foram coletados em um estabelecimento classificado como matadouro-frigorífico misto, com Serviço de Inspeção Estadual (SIE), localizado no município de Atílio Vivacqua, na região sul do estado do Espírito Santo. Foi realizado levantamento referente à quantidade e às causas das condenações de fígados no exame post mortem de bovinos abatidos nos anos de 2008, 2009 e 2010. Após aprovados no exame ante mortem, os bovinos foram liberados para o abate, dando prosseguimento às etapas de: atordoamento, sangria, esfola da carcaça, evisceração e inspeção sanitária das vísceras. As inspeções, na linha de abate, foram realizadas por auxiliares de inspeção e médicos veterinários do SIE de acordo com critérios de condenações de vísceras oficialmente vigentes.

Os bovinos abatidos durante o período foram provenientes de diferentes municípios da região sul do estado do Espírito Santo. Durante os três anos do levantamento, 102.492 animais foram abatidos e inspecionados, e destes, 44.587 $(43,5 \%)$ apresentaram lesões ou alterações hepáticas diagnosticadas na rotina da Linha "E" de inspeção (Tab. 1).

Tabela 1. Número de bovinos abatidos, número de fígados condenados e o percentual de condenações nos anos de 2008, 2009 e 2010

\begin{tabular}{cccc}
\hline Ano & Número de bovinos abatidos & $\begin{array}{c}\text { Número de fígados } \\
\text { condenados }\end{array}$ & $\begin{array}{c}\text { Percentual de condenação } \\
(\%)\end{array}$ \\
\hline 2008 & 33465 & 13466 & 40,24 \\
2009 & 33874 & 14083 & 41,57 \\
2010 & 35153 & 17038 & 48,47 \\
\hline Total & 102492 & 44587 & 43,50 \\
\hline & & Fonte: IDAF
\end{tabular}

O quantitativo de fígados condenados por apresentarem algum tipo de lesões ou alterações hepáticas variou de 40,2\% e 48,5\%. Esse

Recebido em 12 de maio de 2011

Aceito em 1 de setembro de 2011

*Autor para correspondência (corresponding author)

E-mail: peterbfvet@yahoo.com.br percentual é extremamente elevado em relação aos resultados de alguns autores, como: Baptista (2008), com $12,7 \%$ de condenação para todo o estado do Espírito Santo; Bonesi et al. (2003), 
com $6,8 \%$ no oeste e planalto de Santa Catarina; Mendes e Pilati (2007), com 31,7\% em Maringá, no Paraná; e Oliveira et al. (2005), com 7,1\% em Campos do Goytacazes, no Rio de Janeiro. O resultado representa uma perda econômica substancial, por se tratar de uma víscera nobre e de alto valor comercial, sendo uma das mais apreciadas pelo consumidor.

Das condenações hepáticas, as alterações encontradas com maior frequência foram decorrentes da infecção por Fascíola hepática (Tab. 2). A fasciolose hepática, também conhecida como distomatose hepática, foi a principal causa de condenação encontrada no período analisado. $\mathrm{O}$ valor encontrado para condenação de fígados por fasciolose, de acordo com Bonesi et al. (2003), foi de 0,07\%, no Paraná, e de 38,6\%, no Espírito Santo (Baptista, 2008). Mendes e Pilati (2007), em Santa Catarina, relataram média de $18,5 \%$ e citaram que os valores acerca dessa parasitose podem variar em razão das condições de manejo em cada região de criação.

Segundo Fraga (2008), as discrepâncias quanto às condenações por parasitoses normalmente podem ser atribuídas à distribuição epidemiológica do parasito, e no Espírito Santo a fasciolose é uma parasitose emergente, sendo um problema econômico-social da região sul do estado, chegando a atingir cerca de $20 \%$ dos bovinos abatidos.

Tabela 2. Quantitativo e percentual das causas de condenação de fígados bovinos na linha "E" de inspeção decorrente do abate de 102.492 bovinos

\begin{tabular}{lccc}
\multicolumn{1}{c}{ Causa } & Número de condenações & Percentual (\%) & Prevalência (\%) \\
\hline Fasciolose & 27709 & 62,15 & 27,04 \\
Teleangectasia & 5428 & 12,17 & 5,30 \\
Hemorragia & 2617 & 5,87 & 2,55 \\
Abscesso & 2317 & 5,20 & 2,26 \\
Cisticercose & 1786 & 4,01 & 1,74 \\
Aderência & 1630 & 3,66 & 1,59 \\
Contaminação & 844 & 1,89 & 0,82 \\
Tuberculose & 473 & 1,06 & 0,46 \\
Outros & 1783 & 3,99 & 1,74 \\
\hline \multicolumn{1}{c}{ Total } & 44587 & 100,00 & 43,50 \\
\hline \multicolumn{1}{c}{} & & & Fonte: IDAF.
\end{tabular}

A segunda maior causa de condenações foi a de lesões por teleangiectasia. Este achado é menor que os valores citados por Baptista (2008), de $24,6 \%$, por Bonesi et al.(2003), de $41,6 \%$, por Mendes e Pilati (2007), de 32,3\%, e por Oliveira et al. (2005), de 40,2\%. É comum fígados acometidos por esta alteração serem condenados durante a inspeção em razão do aspecto repugnante do órgão. Mendes e Pilati (2007) constataram que a maioria dos fígados condenados por teleangiectasia não apresentava células inflamatórias nem outro processo patológico e poderia ser destinada ao consumo humano, sugerindo que somente os órgãos com grau acentuado de telangiectasia sejam condenados.

De acordo com Baptista (2008), a frequência de fascíola hepática pode influenciar nos resultados de todas as outras patologias, pois fígados que apresentem algum tipo de lesão e/ou alteração juntamente com fascíola hepática geralmente são quantificados em relação ao parasita e não pelas outras alterações patológicas.

O Cysticercus bovis foi contabilizado de acordo com a presença do parasito, independentemente de ser vivo ou calcificado. Foram contabilizadas, também, vísceras de carcaças condenadas independentemente da detecção ou não do parasito nos órgãos. $O$ índice de condenação encontrado é bem próximo do citado por Baptista (2008), 4,2\%. Da mesma forma, nas condenações por tuberculose, as vísceras de carcaças condenadas foram contabilizadas, e o índice obtido foi próximo ao apresentado por Baptista (2008), de $0,92 \%$. É importante registrar que a região sul capixaba é importante bacia leiteira do estado.

A ocorrência da aderência apareceu em sexto lugar com causa de condenação. Mendes e Pilati (2007) relataram prevalência de $6,0 \%$ de condenações e citaram que a ocorrência, muitas 
vezes, tem julgamento incorreto, pois fígados com aderência ao diafragma não apresentam reações inflamatórias agudas, podendo ser destinados ao consumo.

As perdas por hemorragia e contaminação cresceram consideravelmente no decorrer dos três anos pesquisados (Tab. 3) e foram, respectivamente, a terceira e a oitava causa de condenações com $5,9 \%$ e $1,9 \%$ das perdas. Congestão hemorrágica e contaminação fecal foram citadas por Bonesi et al. (2003), com valores de $10,7 \%$ e $14,5 \%$, como causas das condenações.

Tabela 3. Quantitativo e percentual das causas de condenações hepáticas na linha "E" de inspeção nos anos de 2008, 2009 e 2010

\begin{tabular}{lcccccc}
\hline \multicolumn{1}{c}{ Causa } & \multicolumn{2}{c}{2008} & \multicolumn{2}{c}{2009} & \multicolumn{2}{c}{2010} \\
\hline & $\mathrm{N}^{\mathbf{0}}$ & $\%$ & $\mathrm{~N}^{\mathrm{o}}$ & $\%$ & $\mathrm{~N}^{\mathrm{o}}$ & $\%$ \\
Abscesso & 786 & 5,84 & 775 & 5,50 & 756 & 4,44 \\
Aderência & 459 & 3,41 & 574 & 4,08 & 597 & 3,50 \\
Cisticercose & 425 & 3,16 & 646 & 4,59 & 715 & 4,20 \\
Contaminação & 133 & 0,99 & 220 & 1,56 & 491 & 2,88 \\
Fasciolose & 8712 & 64,70 & 9028 & 64,11 & 9969 & 58,51 \\
Hemorragia & 451 & 3,35 & 774 & 5,50 & 1392 & 8,17 \\
Teleangectasia & 1800 & 13,37 & 1511 & 10,73 & 2117 & 12,43 \\
Tuberculose & 78 & 0,58 & 164 & 1,16 & 231 & 1,36 \\
Outros & 622 & 4,62 & 391 & 2,78 & 770 & 4,52 \\
Total & 13466 & 100 & 14083 & 100 & 17038 & 100 \\
\hline & & & & & & Fonte: IDAF
\end{tabular}

Estima-se que a causa das perdas por hemorragia ou congestão esteja relacionada ao atordoamento incorreto ou à sangria ineficiente, o que faz com que o fígado acumule sangue. A contaminação, por sua vez, é atribuída a perfurações do trato gastrintestinal ou ao contato das vísceras com o chão. As duas causas são importantes para o setor, pois representam perdas desnecessárias. Essas alterações estão ligadas à não qualificação dos funcionários na linha de abate.

Outras causas como: cirrose, degeneração gordurosa, icterícia, hidatidose, neoplasia, necrose ou provenientes de animais caquéticos, febris ou brucélicos não foram contabilizadas individualmente, mas seu conjunto somou 4,0\% das condenações. Os números anuais de condenação demonstraram, de forma evidente, a presença de enfermidades no rebanho sul capixaba, onde muitas delas estão diretamente relacionadas ao manejo sanitário do rebanho. $\mathrm{O}$ elevado número de condenações por fasciola hepática no sul do estado do Espírito Santo mostra que a fasciolose é um importante problema econômico e de saúde pública na região. Embora a maior parte das perdas envolva a sanidade animal, as de maior importância econômica são as relacionadas à falta de qualificação profissional, pois essas poderiam ser minimizadas, diminuindo, assim, o número desse tipo de condenação.

Palavras-chave: bovino, matadouro-frigorífico, inspeção, fascilose

\begin{abstract}
This survey was carried out in slaughter plants in the southern of the Espírito Santo State in order to study the causes and the percentages of liver condemnation during post mortem examination from 2008 to 2010. The main reasons for the condemnation of cattle livers in routine meat inspection of the State Inspection Service were fasciolosis (62.2\%), telangiectatic (12.2\%), bleeding (5.9\%), abscess (5.2\%), cysticercosis (4.0\%), adherence (3.7\%), infection (1.9\%) and tuberculosis (1.1\%). The hepatic fascioliasis was responsible for most of the lover condemnations, constituting a major challenge to livestock health in the south of the Espírito Santo.
\end{abstract}

Keywords: cattle, slaughterhouse, inspection, fasciolosis 


\section{REFERÊNCIAS BIBLIOGRÁFICAS}

BAPTISTA, A.T. Quantificações das Condenações em Vísceras de Bovinos em 2007 nos MatadourosFrigoríficos do Estado do Espírito Santo registrados no serviço de inspeção estadual. Universidade Castelo Branco, Instituto Brasileiro de PósGraduação Qualittas, 2008. Disponível em: <www.qualittas.com.br/artigos/artigo.php?artigo_id=5 27> Acessado em: 10 dez. 2010.

BONESI, L.G.; SCALONE, B.C.V.; OKANO, W. Lesões hepáticas em bovinos abatidos em matadourofrigorífico. Rev. Hig. Alim., v.17, p.78-83, 2003.

FRAGA, J.C.L. Incidência da fasciolose hepática bovina no Sul do Espírito Santo. Universidade Castelo Branco, Instituto Brasileiro de PósGraduação Qualittas, 2008. Disponível em: <http://www.qualittas.com.br/artigos/artigo.php?artigo _id=126> Acessado em: 08 dez. 2010.
HERENDA, D.; CHAMBERS, P.G.; ETTRIQUI, A. et al. Manual on meat inspection for developing countries. Roma,Itália: Food and Agriculture Organization of the United Nations, 1994. 357p.

LAWRIE, R. A. Ciência da carne. 6.ed. Porto Alegre: Artemed, 2005. 384p.

MENDES, R.E.; PILATI, C. Estudo morfológico de fígado de bovinos abatidos em frigoríficos industriais sob inspeção estadual no oeste e no planalto de Santa Catarina, Brasil, Santa Catarina. Cienc. Rural, v.37, p.1728-1734, 2007.

OLIVEIRA, I.; POMBO, C.R.; SILVA, T.P. et al. Ocorrência de condenações nas linhas de inspeção em matadouros frigoríficos de bovinos no município de Campos de Goytacazes - R.J. In: CONGRESSO LATINO-AMERICANO DE HIGIENISTAS DE ALIMENTOS, 2., 2005, Búzios. Anais... RJ: Editora, 2005. 